\title{
GERENCIAMENTO DE PROJETOS: UM CASO PRÁTICO DE APLICAÇÃO DE METODOLOGIA NA ACADEMIA
}

\author{
S. V. MARTINS*, L. C. SARDINHA, A. P. V. VASCONCELOS E S. L. SANTOS \\ Instituto Federal Fluminense \\ smartins@iff.edu.br*
}

Artigo submetido em outubro/2013 e aceito em dezembro/2013

DOI: $10.15628 /$ rbept.2013.3488

\section{RESUMO}

Este artigo descreve um caso prático de aplicação de metodologia baseada nos princípios de Gerência de Projetos para análise de conformidade e consequente reformulação dos Cursos Superiores de Tecnologia do campus Campos Centro do IFF (Instituto Federal de Educação, Ciência e Tecnologia Fluminense). O objetivo é compatibilizar a oferta de profissionais da área tecnológica com a demanda dos sistemas produtivos regionais à luz das diretrizes da SETEC/MEC (Secretaria de
Educação Profissional e Tecnológica/Ministério da Educação) e do Catálogo Nacional de Cursos Superiores de Tecnologia. Com base em um diagnóstico da situação atual, ações afirmativas subsequentes foram adotadas, tais como: readequação da oferta, com a reformulação de matrizes; inserção de projeto integrador; detecção de causas de evasão e redução desta; e acompanhamento de alunos, elevando o número de concluintes.

PALAVRAS-CHAVE: Tecnologia, Educação, Curso Superior, Gerência de Projetos e Metodologia.

\section{PROJECT MANAGEMENT: A PRACTICAL CASE OF APPLICATION OF A METHODOLOGY IN THE ACADEMY}

\begin{abstract}
This paper addresses a case study of the application of a methodology based on the principles of project management. It aims to evaluate the compliance and subsequent restructuring of Technology Graduate Courses in the IFF (Federal Fluminense Institute of Education, Science, and Technology) campus Campos Centro. The goal is to match the offer of technological professionals with the demand of regional productive systems based on SETEC/MEC (Professional and
\end{abstract}

Technological Education Secretariat and Ministery of Education) guidelines and the National Catalogue of Technology Courses. Based on a diagnosis of the current situation, subsequent affirmative actions were adopted, such as: readjustment of the offer, with the reformulation of the curriculum; integrator project insertion; evasion causes detection and its mitigation; and monitoring of students, increasing the graduate number.

KEYWORDS: Technology, Education, Graduate Course, Project Management and Methodology. 


\section{INTRODUÇÃO}

Os cursos de graduação tecnológica tiveram origem nos anos 60 , respaldados pela Lei 4.024/61 e por legislações subsequentes, criados para atender à demanda da época - Donato (2010). No parecer CNE/CP 29/2002, o Conselho de Educação reafirma que os Cursos Superiores de Tecnologia - CSTs - são cursos regulares de ensino superior, enquadrados no Inciso II do Artigo 44 da LDB. Há várias décadas já estão devidamente consolidados nos países mais avançados, principalmente na América do Norte e na Europa. Tipicamente, diferenciam-se dos bacharelados por apresentar integralização mais curta e especialização restrita e aprofundada. É de sua natureza, também, poderem ser criados, modificados ou descontinuados em função da demanda do mundo produtivo. Estas características de versatilidade, agilidade e flexibilidade contribuem, em larga medida, para que esses países apresentem indicadores de excelência no ensino superior, com percentual elevado da população cursando ou já tendo cursado este nível de ensino. Sucede aí, por conseguinte, claro impacto na produção científica e tecnológica local. Diante desse contexto, vantagens como competitividade e empregabilidade são, em âmbito mundial, frequentemente associadas a esta modalidade de ensino.

O Instituto Federal de Educação, Ciência e Tecnologia Fluminense (IFF, 2015) é um dos 38 criados em dezembro de 2008, pelo Governo Federal, a partir dos Cefets, escolas agrotécnicas e aquelas vinculadas às universidades. O projeto de expansão da Rede Federal foi iniciado em 2005. O IFF nasce voltado para o mundo do trabalho com a responsabilidade de contribuir para o desenvolvimento socioeconômico e tecnológico das regiões onde está instalado. A oferta de cursos leva em conta o arranjo produtivo local com o intuito de garantir a permanência dos estudantes em suas próprias regiões. No contexto do IFF, a educação superior abrange curso superiores de tecnologia, cursos de licenciatura, cursos de bacharelado, cursos de pós-graduação lato sensu de aperfeiçoamento e especialização e cursos de pós-graduação stricto sensu de mestrado.

Em nosso país, os CSTs experimentaram uma notável expansão nas últimas décadas. Todavia, seja por seu caráter inovador, seja pela existência de uma cultura local bacharelesca, esses cursos têm sido alvo de críticas e enfrentam uma crise de identidade, com reflexos negativos na formação universitária como um todo. Paradoxalmente, ao tempo em que o país carece de profissionais especialistas e tem apresentado um crescimento econômico e social significativo, existe ainda forte cultura de se privilegiar a formação de bacharéis, que representam cursos mais rígidos, demorados e onerosos. Entretanto, a necessidade de profissionais com formação mais voltada para áreas específicas e estratégicas para o desenvolvimento do país abre possibilidades para outras modalidades de formação. Não há que se imaginar que a defesa seria no sentido de uma opção "menor" ou "aligeirada", como muitos definem esses cursos, sem o devido conhecimento de seus objetivos. Os CSTs devem ser identificados como aqueles que trazem a forte presença das tecnologias, o que pressupõe que estejam em constante renovação face ao avanço destas.

A despeito disso, atualmente no IFF, pode-se contar apenas com percepções difusas e intuitivas desta problemática por parte dos profissionais de educação envolvidos, o que acarreta não respaldar decisões judiciosas a respeito. Esta visão distorcida decorre, provavelmente, da dificuldade de reconhecimento e inserção deste profissional no setor produtivo regional. Tendo como pano de fundo este cenário, o IFF câmpus Campos Centro, aplicando as boas práticas do Gerenciamento de Projetos, produziu em 2011/2012 uma radiografia ampla, qualitativa e 
quantitativa, da realidade de seus CSTs, trazendo à tona fatos e dados realistas, interna e externamente, e se serviu destes para orientar a reestruturação de seus cursos na direção do melhor ensino público, através do projeto intitulado Tecnoproj.

O Tecnoproj, organizado valendo-se de uma série de etapas e atividades devidamente planejadas à luz dos princípios da disciplina de Gerência de Projetos, desenvolveu pesquisas, análises dos dados coletados, e, consequentes ações, pautadas nos temas a seguir: evasão escolar; dificuldades na inserção socioprofissional dos egressos; necessidade de revisão da estrutura acadêmica, buscando elevação da qualidade dos processos formativos; necessidade da diversificação da oferta de cursos, especialmente os inovadores, sintonizados com as demandas que contribuam para o desenvolvimento local e regional.

Diante do exposto, o objetivo deste artigo é apresentar o desdobramento e os resultados atingidos pelo Tecnoproj, em todas as dimensões investigadas, a saber: setor produtivo, alunos em curso, alunos evadidos, egressos, professores, coordenações de curso e instituições parceiras. Esse artigo está organizado da seguinte forma: a Seção 2 descreve a metodologia adotada; a Seção 3 aborda a primeira etapa do projeto Tecnoproj, através do diagnóstico da situação atual, embasado pelos resultados de pesquisas de campo; a Seção 4 destaca as ações desenvolvidas na segunda etapa do projeto, com base nos resultados obtidos nas pesquisas e a Seção 5 traz os resultados obtidos com este trabalho, bem como as lições aprendidas, suas melhores práticas e sugestões de trabalhos futuros.

\section{METODOLOGIA DE GERENCIAMENTO DE PROJETOS APLICADA}

Faz-se nesta seção uma breve incursão pela disciplina de Gerenciamento de Projetos com o propósito de ganhar visão abrangente do trabalho em tela. Em português pode emergir alguma ambiguidade com a semântica do termo projeto. Portanto, é recomendável destacar que projeto aqui é tomado como sinônimo de empreendimento, obra, i.e, implica um conjunto de tarefas a serem planejadas, executadas, controladas e encerradas e demandando algum tipo de recurso com o objetivo final de alcançar determinada meta. Ademais, projetos podem ser classificados em diversas categorias: marketing, administrativos, pesquisa, construção civil etc.

A abordagem empregada toma por base o que preconiza o guia PMBOK (2013), referência mundial na disciplina, o qual identifica 47 processos gerenciais e dez áreas de conhecimento: prazo, custo, qualidade, escopo, contratação, comunicações, riscos, recursos humanos, stakeholders (partes interessadas) e integração. Gerenciar um projeto, então, consiste em executar os processos gerenciais sobre as dez áreas de conhecimento, durante o seu ciclo de vida, para atingir a meta preestabelecida. Os processos são reunidos em cinco grupos distintos (iniciação, planejamento, execução, monitoramento e controle e encerramento), que podem ser tomados como fases do projeto, as quais não são estanques e sucessivas, mas se superpõem parcialmente em algum período, no decurso do projeto, havendo alternância no predomínio de cada uma delas, conforme o trabalho avança tal como se pode deduzir da Figura 1. Essas fases, quando tomadas em conjunto, recebem o nome de ciclo de vida do projeto, o qual circunscreve seu período de início e término. 


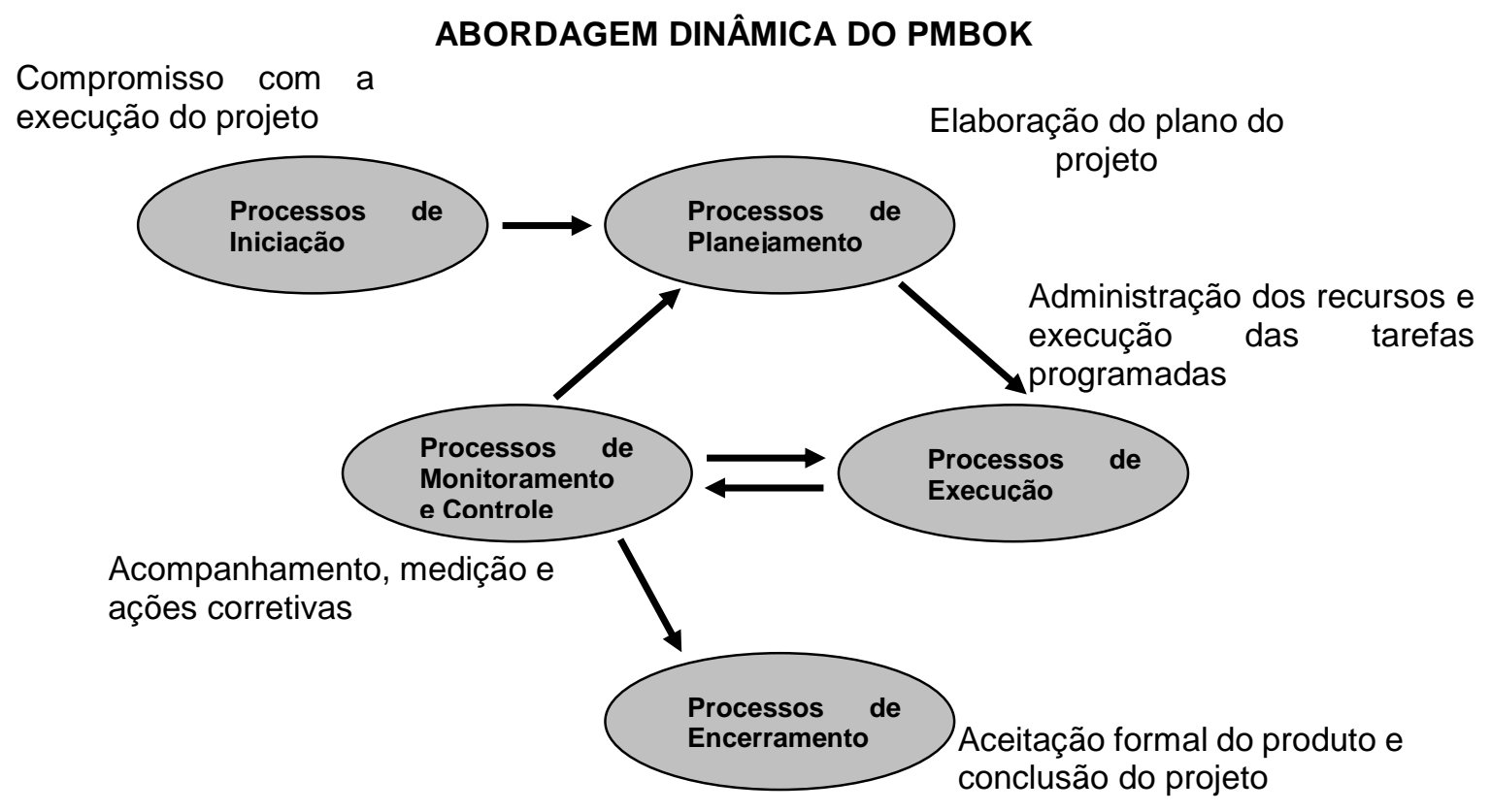

Figura 1: Fluxograma da dinâmica dos grupos de processos do PMBOK (2013).

Objetivando levar a cabo o escopo do Tecnoproj de modo otimizado, empregou-se uma metodologia própria e simplificada de gerenciamento de projetos. Como se tratou de projeto de médio porte e num ambiente acadêmico público, algumas áreas de conhecimento foram desconsideradas, como, por exemplo, riscos e custo.

$\mathrm{Na}$ fase de inicialização, elaborou-se documento seminal intitulado Termo de Abertura do Projeto, no qual os dados básicos são sucintamente descritos - cf. Anexo 1 - e tem o propósito precípuo de firmar compromisso entre os stakeholders, eleger um gerente e tornar pública a iniciativa.

Em sua fase de planejamento, culmina com o Plano de Trabalho, contemplando componentes tais como dados institucionais, dados do projeto (equipe executora, objetivos, motivação e justificativa, resultados esperados, e regulamento do projeto), matriz de responsabilidades e elencando as tarefas associadas às três etapas em que se dividiu o projeto: (1) Diagnóstico da Situação Atual; (2) Reestruturação dos CSTs e (3) Encerramento do Projeto. Nas seções seguintes, estas etapas são pormenorizadas. O plano também incluiu o cronograma do projeto (gráfico de Gantt), que pode ser examinado na Figura 2 a seguir. 


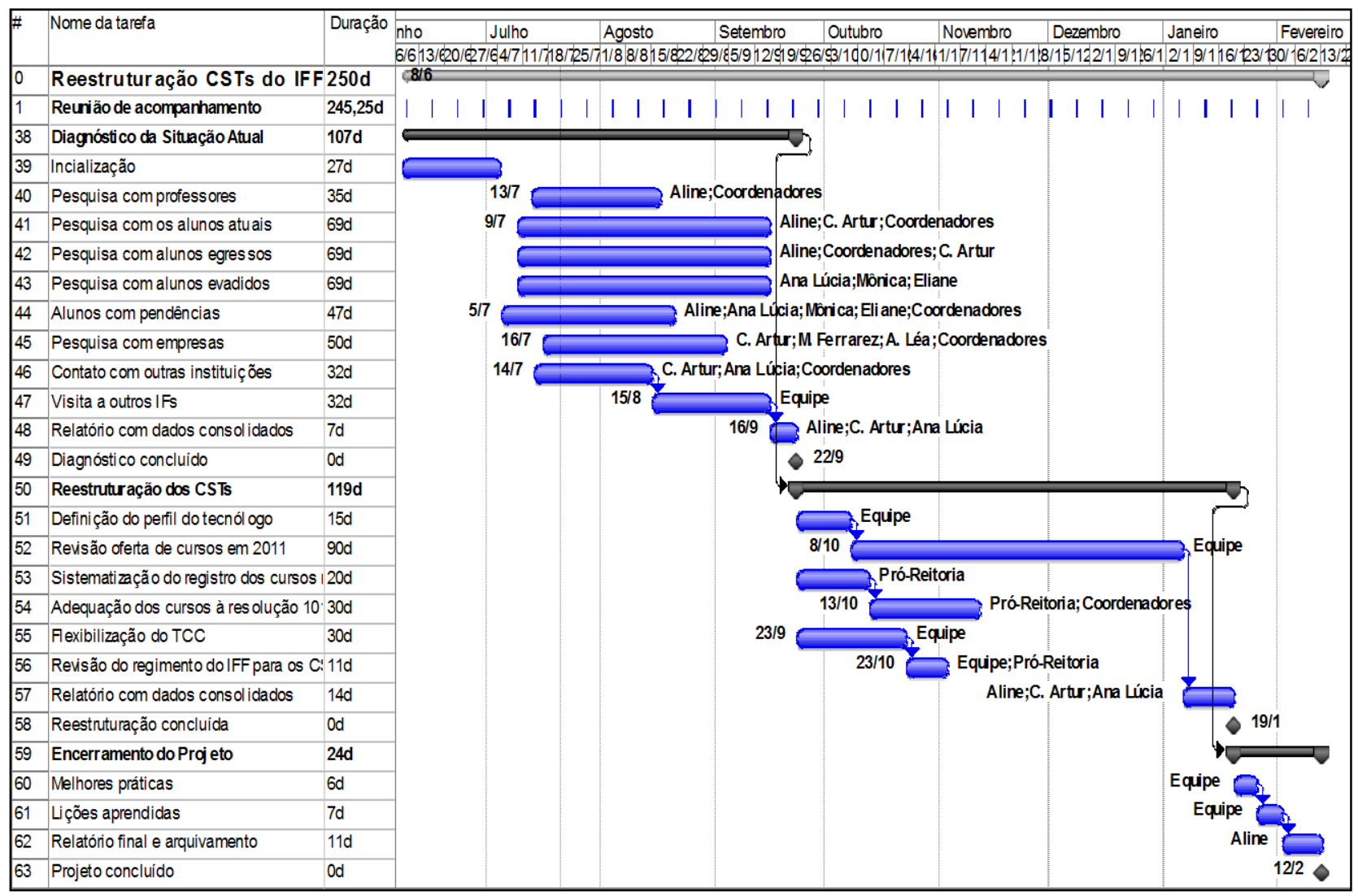

Figura 2: Cronograma do projeto Tecnoproj.

Enquanto a fase de execução propriamente dita acontecia, na forma de viagens e tarefas adiante descritas, ao mesmo tempo a fase de monitoramento e controle transcorria, especialmente durante reuniões semanais.

A fase dos processos de encerramento, uma vez dado por concluído o Tecnoproj, englobou a identificação de lições aprendidas e melhores práticas a serem aplicadas em projetos futuros e redação de relatório final.

\section{PRIMEIRA ETAPA DE DESENVOLVIMENTO DO TECNOPROJ}

Foram realizadas diversas pesquisas, a saber: com docentes, discentes, egressos, evadidos, empresas e outras instituições de ensino, de mesma natureza dos Institutos Federais ou não, mas que atuam com CSTs. Essas pesquisas tiveram o intuito de complementar o trabalho realizado internamente pela CPA (Comissão Própria de Avaliação), com foco nas questões que necessitavam ser tratadas para os CSTs. As pesquisas, com base em questões já elaboradas por outras instituições e em algumas demandas provenientes das próprias coordenações de curso dos CSTs, foram discutidas e refinadas nas reuniões periódicas desse grupo de trabalho. Segue o detalhamento de cada uma das ações de pesquisa realizadas.

\subsection{Pesquisa com professores}

Se deu por meio de reuniões de parte do grupo de trabalho com os respectivos docentes. Para cada curso, reuniu-se com os professores, a fim de explicar e passar o questionário, a seguinte equipe: o Coordenador de Curso do CST em questão, o Diretor de Ensino da área correlata e um 
pedagogo. A distribuição dos questionários avaliativos teve o propósito de colher as impressões gerais dos docentes envolvidos nos cursos de modo a definir ações reestruturantes. As seguintes dimensões foram abordadas: avaliação geral do curso; inserção do egresso no setor produtivo e o alinhamento do seu perfil de formação a este; causas e possíveis soluções para a evasão escolar; e a abordagem do Trabalho de Conclusão de Curso (TCC) na integração curricular.

\subsection{Pesquisa com estudantes}

Envolveu a aplicação de questionários para os alunos que se encontravam regularmente matriculados nos CSTs com o objetivo de delinear o seu perfil (ex: trabalha, faz estágio, formação anterior etc.), avaliar motivações, dificuldades, interesses e expectativas.

\subsection{Pesquisa com estudantes evadidos}

O objetivo desta pesquisa foi a realização do mapeamento do cenário de evasão nos últimos 3 anos, a contar da data de início do projeto Tecnoproj, nos CSTs do IFF câmpus Campos Centro. A partir do levantamento da relação dos alunos evadidos nos CSTs neste período, organizou-se uma entrevista com esses ex-alunos, por telefone, na qual foi respondido questionário com perguntas visando identificar fatores, como: causas da evasão, tempo de permanência no referido curso, a situação do ex-aluno após o abandono e o interesse em retornar ao curso. A Tabela 1 apresenta um resumo das principais causas de evasão nos cursos identificadas à época.

Tabela 1: Tabela resumo das causas de evasão nos CSTs.

\begin{tabular}{c|c}
\hline Causas da Evasão & $\begin{array}{c}\text { Percentual de } \\
\text { Respondentes }\end{array}$ \\
\hline $\begin{array}{c}\text { O curso não estava de acordo com a } \\
\text { necessidade do mercado de trabalho } \\
\text { Horário incompatível com seu horário de } \\
\text { trabalho }\end{array}$ & $1 \%$ \\
Dificuldade com determinada(s) disciplina(s) & $45 \%$ \\
Problema com professor(es) & $3 \%$ \\
Fez opção por outro curso? & $2 \%$ \\
Dificuldade com TCC/Projeto Final & $10 \%$ \\
Mudança de cidade & $5 \%$ \\
Mudança de emprego & $4 \%$ \\
Dificuldade financeira & $1 \%$ \\
Problemas de saúde pessoal ou na família & $1 \%$ \\
Não achou o ensino de qualidade & $5 \%$ \\
Outro & $2 \%$ \\
\hline
\end{tabular}


Razões como a dificuldade com o Trabalho de Conclusão de Curso e a opção por outro curso foram fortes motivadores para o abandono, conforme pode ser observado pelo gráfico. Por fim, a pesquisa apontou um forte interesse pelos entrevistados em retornar oportunamente ao curso.

\subsection{Pesquisa com egressos}

Contemplou entrevistas com profissionais formados pelos cursos, a partir das quais foi possível realizar sua melhor adequação à realidade do setor produtivo. Foram abordadas questões como: situação de trabalho (conformidade do vínculo empregatício com a formação), nível de satisfação com a conjuntura na qual se encontra, avaliação do curso e da instituição de ensino, pontos positivos e negativos detectados ao longo da integralização curricular, correlação curricular do curso com as demandas do setor produtivo, sugestões para melhoria destes. As Figuras 3 e 4 apresentam uma visão do resultado da pesquisa sob o ponto de vista da adequação do trabalho à formação para os cursos de Sistemas de Telecomunicações e Manutenção Industrial.

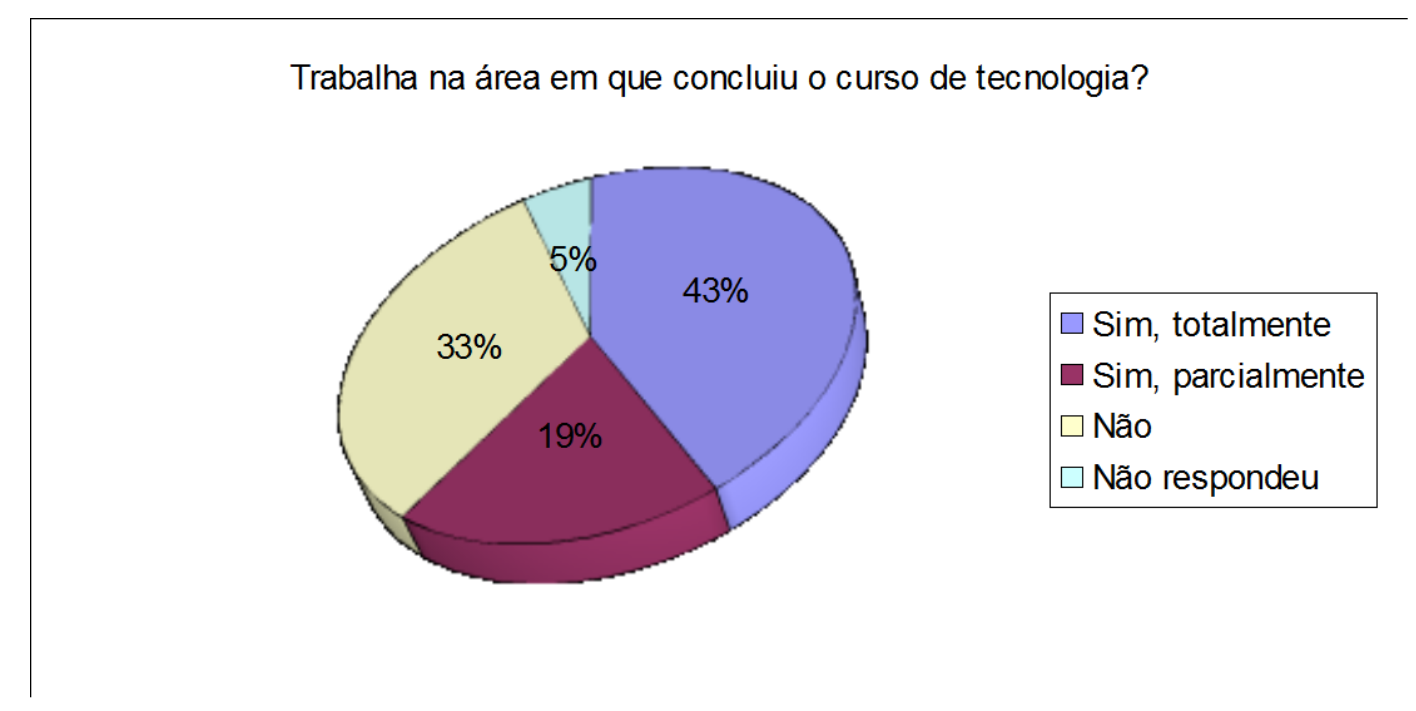

Figura 3: Gráfico Resumo da Adequação da Formação para o CST em Sistemas de Telecomunicações.

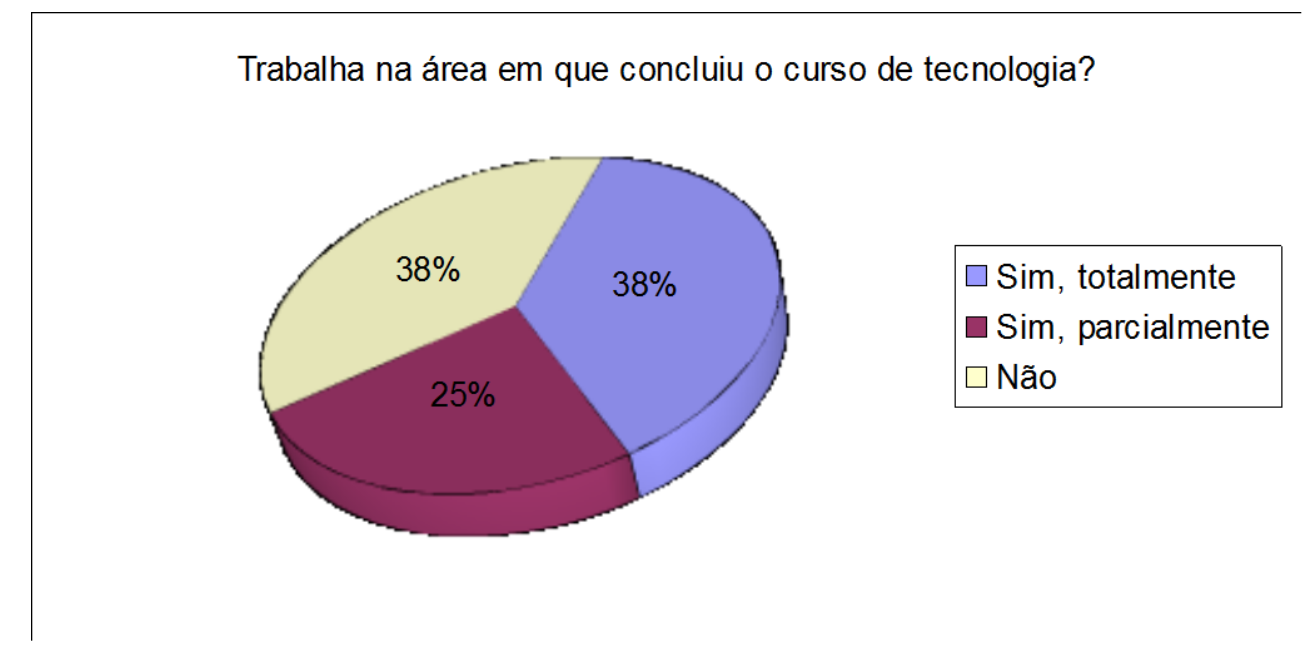

Figura 4: Gráfico Resumo da Adequação da Formação para o CST em Manutenção Industrial. 
Dessa forma, constata-se que a maioria dos egressos, à época, trabalhava na área de formação do curso. A despeito disso, em função do predomínio da Petrobras na região Norte Fluminense do estado do Rio de Janeiro, muitos desses egressos não exerciam funções de nível superior.

\subsection{Pesquisa com empresas}

Nesta etapa, a ideia básica foi de se estabelecer contato com os verdadeiros anseios dos sistemas produtivos regionais no que tange ao perfil dos profissionais tecnólogos. Como estratégias para consolidação deste contato, foi produzido e distribuído material de divulgação de alta qualidade, na estrutura similar a de um catálogo, bem como repassado questionário, a fim de fortalecer a relação escola-empresa. Foram abordadas questões nas seguintes dimensões: conhecimento sobre a natureza dos CSTs, contratação deste perfil de profissional, adequação deste profissional e sugestões para atualizações curriculares ou para a criação de novos cursos. As empresas selecionadas para esta entrevista foram aquelas cadastradas na Agência de Oportunidades do IFF câmpus Campos Centro.

\subsection{Pesquisa com outras instituições de ensino}

Este mapeamento teve como foco central as seguintes dimensões: empregabilidade dos egressos, condução e normativa de realização de Trabalho de Conclusão de Curso, questão da evasão e políticas de seu combate e a gestão pedagógico-administrativa do currículo dos cursos. A seleção das instituições para a visita se deu com base na afinidade curricular das propostas de oferta de cursos e com base na busca da diversidade de perfis institucionais, localizados em diferentes regiões do país, a saber: instituições privadas e instituições públicas, neste último caso, envolvendo institutos e universidade tecnológica. Foram visitadas instituições nos estados de São Paulo, Rio de Janeiro, Bahia e Paraná. A partir de algumas destas visitas, foi possível obter informações sólidas sobre o cenário em que se encontram os CSTs em cada região.

No estado de São Paulo, a instituição visitada apresentou a seguinte realidade: egressos empregados, porém não se sabe ao certo se como técnicos ou como profissionais de nível superior; o estágio é obrigatório, bem como existe prazo máximo de integralização do curso, correspondendo ao dobro do tempo da proposta curricular.

Em Volta Redonda, algumas empresas reconhecem o profissional de tecnologia como de nível superior. O estágio é obrigatório e os TCCs são de natureza mais focada e objetiva, não sendo exigido aos alunos um extenso trabalho de pesquisa e referencial teórico para o seu desenvolvimento. Esta realidade de reconhecimento do profissional estabelece um contraponto em relação à mesorregião Norte Fluminense deste mesmo estado em função da Petrobras, que predomina como grande empresa neste cenário.

No Paraná, a proposta foi de se conhecer a realidade do CST em uma universidade e na região. Informações como mercado de trabalho favorável e baixo índice de evasão fomentam a manutenção da permanência da oferta desta modalidade de curso. O TCC pode ser realizado em conjunto com outro curso, numa proposta pluricurricular, com professores orientadores de cada área trabalhando de forma articulada em conjunto. $O$ egresso é inserido no mercado em funções de supervisão, coordenação de trabalhos e assessoria. 


\section{SEGUNDA ETAPA DE DESENVOLVIMENTO DO TECNOPROJ}

A partir do diagnóstico da situação atual realizado na primeira etapa do Tecnoproj e descrito nas seções anteriores, o trabalho prosseguiu na direção da reformulação estrutural destes CSTs e no estabelecimento de uma política para combate à evasão e retenção, implicando em iniciativas, como: revisão dos itinerários formativos; revisão da condução dos Trabalhos de Conclusão de Curso; inserção do Projeto Integrador em Projetos Pedagógicos de Cursos (PPCs), com o intuito de permitir que o aluno trabalhe a interdisciplinaridade na sua proposta curricular; análise da necessidade de descontinuidade ou criação de cursos; bem como a adoção de medidas de caráter pedagógico-administrativas. Segue detalhamento das ações supracitadas.

\subsection{Revisão dos itinerários formativos nos PPCs}

Com base nos resultados das pesquisas com alunos em curso, egressos e alunos evadidos, foi constatada a necessidade de revisão dos itinerários formativos de alguns cursos, a fim de tornálos mais atraentes e motivadores na sua integralização. A pesquisa com empresas também ajudou a subsidiar a reformulação dos currículos dos referidos cursos. Nesse sentido, houve a transposição de disciplinas entre períodos - trazendo para períodos iniciais disciplinas de cunho prático, para as quais não havia pré-requisitos na matriz - e reformulação dos conteúdos programáticos das disciplinas de línguas, a fim de dividir a carga horária entre períodos, permitindo uma evolução gradual, além de maior adaptação ao perfil técnico dos CSTs. Além disso foi feita revisão dos conteúdos programáticos e da oferta de determinadas disciplinas no núcleo profissionalizante, como, por exemplo, de disciplinas referentes a qualidade de vida e saúde.

\subsection{Revisão da condução dos TCCs}

A necessidade de revisão na condução dos Trabalhos de Conclusão de Curso em razão do alto índice de retenção e adoção por outras instituições de ensino visitadas de metodologias distintas mais flexíveis, não exigindo, necessariamente, um trabalho monográfico.

Como resultado, o TCC, no CST de Manutenção Industrial, que anteriormente era desenvolvido exclusivamente através de monografia, passou a ser viabilizado por meio de um dos mecanismos a seguir: monografia, relatório de estágio oficializado pelo IFF, artigo científico publicável, trabalho de pesquisa com relatório, projeto técnico com relatório.

Por outro lado, no CST em Design Gráfico, a flexibilização se deu admitindo, além da monografia, novas possibilidades, nomeadamente: projeto prático, protótipo e memorial descritivo; e artigo publicado.

\subsection{Inserção de projeto integrador nos PPCs}

Entende-se por projeto integrador um componente da matriz curricular, estabelecido com base no parecer 239/2008 do Conselho Nacional de Educação (CNE). O Projeto Integrador (PI) apresenta uma abordagem interdisciplinar com os diversos saberes específicos, interagindo para incutir no aluno o sentido holístico do curso e que pode se tornar uma base para o Trabalho de Conclusão de Curso. No CST em Manutenção Industrial, prevê-se para o PI uma carga horária de 60 horas-aula por período, totalizando 180 horas-aula, envolvendo todas as disciplinas técnicas e gerenciais, e tendo como eixos temáticos a Gerência de Manutenção Industrial e a Execução da 
Manutenção Industrial. O CST em Manutenção Industrial foi selecionado pelo grupo do Tecnoproj como curso-piloto para a aplicação desta metodologia.

Seguem exemplos destes projetos interdisciplinares, com as disciplinas integradas:

1. Desenho de peças. $\rightarrow$ Elementos de máquinas e Desenho assistido por computador (CAD);

2. Sistemas de Sustentação, Rotação e Circulação de uma Plataforma de Petróleo $\rightarrow$ Petróleo e Inglês técnico;

3. Lubrificação $\rightarrow$ Lubrificação e Estatística;

Como pontos negativos, citam-se a dificuldade de engajamento por parte de alunos e professores na proposta do $\mathrm{Pl}$, bem como a disponibilidade de professores disponíveis para orientação. Como vantagem desse Projeto Integrador, tem-se a melhor visualização por parte dos alunos no entendimento do contexto integrado, aprimorando o conhecimento das partes que levam a uma visão holística do todo.

\subsection{Descontinuidade ou criação de cursos}

Com base nos resultados do diagnóstico da situação atual, constatou-se necessidade de se magnificar a empregabilidade dos egressos. Dessa forma, para cada um dos eixos tecnológicos em que o IFF câmpus Campos Centro oferta cursos, a seguinte análise e tomada de decisão foram conduzidas:

- Eixo tecnológico de controle e processos industriais: neste segmento, optou-se pela descontinuidade do CST em Sistemas Elétricos devido ao alto índice evasão e dificuldade de empregabilidade do egresso, estando em andamento a construção do PPC de uma Engenharia Elétrica na instituição.

- Eixo Tecnológico de produção cultural e design: neste eixo, uma vez que não existe regulamentação por órgãos de fiscalização das profissões e que, consequentemente, a absorção da mão de obra pelo setor produtivo não é comprometida, optou-se por manter a oferta do CST em Design Gráfico, com a devida reformulação curricular proveniente do projeto Tecnoproj.

- Eixo de informação e comunicação: no IFF câmpus Campos Centro eram ofertados neste eixo os CSTs em Análise e Desenvolvimento de Sistemas e em Sistemas de Telecomunicações, bem como o Bacharelado em Sistemas de Informação. Uma vez que o CST em Análise e Desenvolvimento de Sistemas apresenta perfil muito abrangente e generalista para um curso de tecnologia, optou-se por sua descontinuação e manutenção do bacharelado na área.

\subsection{Adoção de medidas de caráter pedagógico-administrativas}

Neste âmbito, ações como a criação do edital de Reingresso para Alunos Evadidos foram tomadas, no intuito de recuperar alunos que, por algum motivo, se desligam temporariamente do curso. Outra ação advinda dos Colegiados de Curso foi a necessidade de um melhor aparelhamento dos laboratórios para uma culminância na qualidade das aulas de natureza prática. Os cursos de Design Gráfico, Sistemas de Telecomunicações e Manutenção Industrial identificaram suas demandas e estas foram prontamente atendidas pela Diretoria de Ensino Superior do IFF campus Campos Centro. 


\section{CONSIDERAÇÕES FINAIS}

Após a realização de todas as etapas previstas no Tecnoproj, envolvendo o diagnóstico da situação atual, a tomada de medidas e o desenvolvimento de ações propositivas, podem-se citar alguns resultados obtidos de caráter significativo, como os descritos a seguir. Além disso, as melhores práticas da condução do projeto, bem como as lições aprendidas e proposições de trabalhos futuros, são destacadas.

\subsection{Resultados obtidos}

Como resultados significativos obtidos com este trabalho e apontados pela Diretoria de Ensino Superior do IFF campus Campos Centro, destacam-se:

- a reformulação dos Projetos Pedagógicos dos Cursos;

- o retorno de alunos que se consideravam evadidos;

-o aumento substancial do número de formandos em relação aos semestres anteriores, em especial nos cursos de Design Gráfico e Análise e Desenvolvimento de Sistemas;

- redução dos índices de retenção dos alunos nas novas propostas curriculares;

- início de contratação de egressos, por parte de algumas empresas, na condição apropriada de profissionais tecnólogos graduados tal como de fato são.

Quanto à significativa elevação do número de formandos, o novo cenário se manifestou de forma muito satisfatória no decorrer das ações advindas do Tecnoproj, conforme apresentado no quadro a seguir. Este trabalho se iniciou em 2010 e, em relação ao ano de 2009, cujo total de formandos foi de 61 estudantes nos CSTs do campus, o índice se elevou em 177\%. Observa-se por este alto índice que em função dos trabalhos realizados no Tecnoproj, foi possível se resgatar alunos evadindo-se ou já evadidos desses cursos. Pelo depoimento do grupo de trabalho, o sucesso se deu devido ao empenho integrado de todos os profissionais e, em especial dos coordenadores dos cursos, no sentido do acompanhamento desses estudantes para desenvolvimento e defesa de TCCs, uma das principais dificuldades apresentadas para a integralização de curso.

Porém, nos anos subsequentes ao desenvolvimento do Tecnoproj (i.e. 2012, 2013...), os bons índices de formandos, em geral, não se mantiveram, pois coube a cada curso a manutenção ou não das políticas e ações propostas no projeto. No CST em Design Gráfico, observa-se uma regularidade no índice de formandos, uma vez que o colegiado primou e vem se dedicando à flexibilização e acompanhamento dos alunos em TCC. Nos casos da Informática e Sistemas Elétricos, houve a descontinuidade dos cursos.

Em relação à Manutenção Industrial, os resultados da implementação da nova matriz com projeto integrador e flexibilização do TCC só começarão a ser percebidos na prática a partir da conclusão da primeira turma neste novo currículo, o que ocorrerá no final do ano letivo de 2014. No Curso Superior de Tecnologia em Sistemas de Telecomunicações, a reformulação da matriz foi implementada somente em 2014, e dessa forma após integralização da primeira turma nessa nova proposta curricular, prevista para 2014, será possível avaliar no referido ciclo a redução dos índices de evasão e retenção. 
Tabela 2: Número de formandos nos CSTs no Período de 2009 a 2013.

\begin{tabular}{l|l|l|l|l|l}
\hline CURSOS & 2009 & $2010^{*}$ & 2011 & 2012 & 2013 \\
\hline Design gráfico & 11 & 64 & 39 & 16 & 34 \\
Manutenção Industrial & 5 & 18 & 19 & 1 & 7 \\
Informática & 34 & 58 & 21 & 10 & 6 \\
Sistemas Elétricos & 2 & 14 & 4 & 6 & 8 \\
Telecomunicações & 9 & 15 & 1 & 0 & 7 \\
\hline
\end{tabular}

Outra medida a ser adotada na perspectiva da permanência e sucesso dos estudantes é a adoção de metodologias com apoio das tecnologias da informação e da comunicação (TIC). A atuação primeira será com a disciplina de Cálculo, responsável por um grau elevado de reprovações nos cursos e evasão. Numa ação conjunta com o Programa Tecnologia Comunicação e Educação (PTCE), que vem disponibilizando suporte para um trabalho online e pedagógico de apoio aos professores, pretende-se oferecer um acompanhamento e reforço para os alunos em disciplinas em que estes apresentam maior dificuldade.

\subsection{Melhores práticas}

Como melhores práticas registradas no desenvolvimento deste projeto, destacam-se:

- a condução do trabalho com base no Plano do Projeto e no Cronograma

- elaborados no início deste, os quais orientaram o andamento das ações desenvolvidas;

- realização de visitas a outras instituições de ensino que ofertam Cursos Superiores de Tecnologia, permitindo o intercâmbio de informações e trazendo feedback importante para a reformulação dos cursos;

- uso de ferramenta para o compartilhamento de documentos, facilitando o trabalho em equipe;

- reuniões semanais de trabalho com horário de início e fim, seguindo uma pauta e cronograma de atividades;

- elaboração de cartilha dos CSTs para divulgação.

\subsection{Lições aprendidas}

Como lições aprendidas com o desenvolvimento do projeto Tecnoproj, destacam-se:

- trabalho junto às empresas de divulgação deve ser mais efetivo;

- na pesquisa com professores, observou-se o pouco envolvimento dos mesmos, sendo necessário repensar a estratégia;

- maior incentivo à integração da Diretoria de Extensão no processo de pesquisa com egressos, a fim de permitir melhor retorno para potencialização de ações de caráter institucional no que tange a estágio e emprego para os alunos e egressos.

\subsection{Trabalhos futuros}

Uma vez finalizado este trabalho, foi detectada a necessidade de acompanhamento contínuo dos cursos que tiveram seus PPCs reformulados, principalmente o de Manutenção Industrial, que inseriu o Projeto Integrador, e o de Sistemas de Telecomunicações, que também 
realizou ampla reestruturação em sua proposta curricular. A conclusão da primeira turma do CST em Manutenção Industrial na nova proposta está prevista para meado de 2015 e para o CST em Sistemas de Telecomunicações a previsão de conclusão é para o ano subsequente. Dessa forma, como trabalhos futuros têm-se a avaliação do desempenho dos egressos neste novo modelo de currículo.

Após a conclusão do Tecnoproj, a metodologia de autoavaliação institucional no IFF foi revisada, tendo sido criada, além da CPA, uma Comissão Local de Avaliação em cada campus (CLA), permitindo a potencialização do processo de avaliação com alunos, egressos, professores etc.

\section{AGRADECIMENTOS}

Penhoradamente, os autores manifestam a sua gratidão pelo empenho na colaboração com o Tecnoproj por parte dos servidores: Ana Lúcia Campinho, Carlos Artur Areas, Carlos Augusto de Oliveira Monteiro, Eliane Paravidino, Hugo Rocha, Maurício José Viana Amorim e Mônica Azevedo de Freitas Almeida.

\section{REFERÊNCIAS BIBLIOGRÁFICAS}

1. AUGUSTA, Degmar. $O$ ensino superior no Brasil: do séc. XIX aos dias atuais. 7/02/2008. Disponível em: <http://www.webartigos.com> Acesso em: 14 de janeiro de 2015.

2. DONATO, Vitório. Introdução á Logística: O perfil do Profissional. Rio de Janeiro: Ciência Moderna, 2010. p.198.

3. GOMES, Cristina Guimarães. OLIVEIRA, Elzira Lúcia de. Curso Superior de Tecnologia como Instrumento de Inserção no Mercado de Trabalho Regional: O caso do Norte Fluminense. 2006. XV Encontro de Estudos Populacionais - ABEP. Caxambu - MG. De 18 a 22 de setembro de 2006.

4. IFF, Instituto Federal de Educação, Ciência e Tecnologia Fluminense. Disponível em: $<$ www.iff.edu.br> Acesso em 11/08/2015.

5. MEC, Ministério da Educação e Cultura. Instituto Nacional de Estudos e Pesquisas Educacionais Anísio Teixeira. Catálogo Nacional de Cursos superiores de Tecnologia. Brasília, DF: INEP/MEC, 2010. p.73

6. MOURA, Fábio Viana; BATISTA, Igor Veloso Colares. Instituições de ensino superior em contabilidade e suas contribuições para a formação de profissionais socialmente responsáveis. 70 Congresso USP - FIPECAFI. Controladoria e Contabilidade em Prol do Desenvolvimento.Universidade de São Paulo (USP), São Paulo, 2007.

7. Prado, D., Planejamento e Controle de Projetos, 5a . ed., Ed. INDG, BH, 2004.

8. Prado, D., Gerenciamento de Programas e Projetos nas Organizações, 6a. ed., Ed. INDG, BH, 2013.

9. Heldman, K., Gerência de Projetos: Fundamentos, Ed. Campus, SP, 2005.

10. Project Management Body of Knowledge - PMBOK, 5a ed., PMI, 2013. 